\title{
THE AFTERLIFE OF DISCARDED WOOLLENS: WHO IS RECYCLING MY CLOTHES?
}

\author{
Anupam Kapoor \\ Research Scholar, National Institute of Fashion Technology, New Delhi, India \\ Ajit Kumar Khare \\ Professor, National Institute of Fashion Technology, Mumbai, India
}

\begin{abstract}
Purpose- This photo shoot aims to document and understand the process, present scenario, facilities and workers condition of wool recycling units in Panipat, a small town in northern part of India. The city emerged as the recycling hub when the owners of Panipat mills bought second-hand machines from Prato, Italy and started recycling wool and producing shoddy yarn. Panipat is acknowledged as the "cast off capital" and is a part of recycling $\$ 182$ million value of worn clothes imported to India annually.

Methodology-In total, 5 wool recycling units were visited for studying the processes and taking photographs. 20 unstructured interviews of workers, 5 unstructured interviews offactory owners, factory managers/ labor contractors each were conducted.

Findings- The findings were categorized into three subheads: The processes, Worker condition and the present scenario. The process of recycling has been same since the inception. With the industry mainly driven by the unorganized sector, there is a lack of investment from the owners towards machinery up -gradation and worker wellbeing. The economic and social aspect of sustainability is lacking in the whole system. Poor working conditions, lowest worker wages and workers prone to respiratory disorders is the other face of the industry that is doing good to the planet by recycling waste.

The industry is on the decline due to competition from the lightweight polyester blanket, almost of the same price, softer in hand feel and of better aesthetics. Large amounts of clothing lie without processing due to the slump in demand. The price of imports per $\mathrm{kg}$ has fallen by almost 3 times as compared to early 1990's when it was approximately $50 \mathrm{Rs} / \mathrm{kg}$ to now at $16 \mathrm{Rs} / \mathrm{kg}$ now. The lightweight polyester substitute, excess supply of second-hand clothing and fall in demand of its recycled products posses many questions about the future of recycling fashion. This is a case where substitutes are cannibalizing sustainability efforts.
\end{abstract}

Implications- The photos from this study have a direct implication on creating awareness of the social impact of overconsumption and over disposal. We need to think beyond eco-friendly disposal. At the time when we are concerned about "who made my clothes", it is also the phase when we ask "Who is recycling my clothes" and what substitutes hamper recycling too. 
Keywords: Wool Recycling, Fashion Recycling, Labor condition, Panipat Recycling Industry

Cite this Article: Anupam Kapoor, Ajit Kumar Khare, The Afterlife of Discarded Woollens: Who is Recycling my Clothes?, International Journal of Management, 10 (5), 2019, pp. 84-98.

http://iaeme.com/Home/issue/IJM?Volume=10\&Issue $=5$

\section{INTRODUCTION}

Second hand clothing trade is a representation of a different picture of how global north and south are linked. It portrays the connection of the richest people of the world to the poorest. Accelerating fashion trends and increase in global clothing wastage without any significant change in the way we produce and market fashion indicates an environment disaster in the making. Total global second hand imports by value have been estimated to be $\$ 2.6$ billion in 2016 as per the analysis of data BBC from the United Nations. According to the report, out of the total imports, India imports $\$ 87.1$ million value of secondhand clothing and stands $4^{\text {th }}$ amongst the biggest secondhand importing nations of the world (Kim, 2018). Resale of used clothes in domestic market is prohibited as per Indian law. Import of used clothes in India is under two categories: mutilated and wearable. The condition on which wearable second hand clothes are imported is that the licensed importer has to do a 100 percent re-export. These are considered to be serving as a charity, chiefly in African countries. This category estimates to be about 30 per cent of the total imports and the mutilated category accounts to almost 60 per cent for which government license is not required. Mutilated clothing yields yarn which is used to make blankets that are used for disaster relief and is sold as charity ranging from 150 Rs to 250 Rs (Acharaya, 2015). The largest suppliers of blankets in the world are Panipat industries, an industrial town in North India, which has been put on global map of recycling. The recycling units in Panipat absorb around 1,44,000 tonnes of mutilated worn clothes per year exported from developed countries (Rebello, 2015). It is known as the "Shoddy" industry which has derived its name from the slang, shoddy yarn, derived from the mutilated clothing. Most of the mutilated clothing imports account for woolen and acrylic clothes because of their limited demand in resale market. The reason for this being, second hand clothing consuming nations situated in warmer climatic zones. This paper aims at documenting the process, worker condition and the present scenario of the wool recycling units of the shoddy industry through photo documentation.

The findings are divided into three sub heads:

- Process followed

- Worker conditions

- Present scinario.

\section{PROCESS}

The mutilated clothes are exported in vacuum packed bundles which are wrapped by plastic and take a form of a bale. Segregation of woolen clothes begins at the exporter's facility where they are divided into four categories (Figure 1):

- CAW bought by Panipat industries at Rs $80 / \mathrm{kg}$. Commercial all wool comprise of woolen sweaters, scarves and knits.

- Acrylic bought at $30 \mathrm{Rs} / \mathrm{kg}$. Includes garments that contain a high percentage of acrylic.

- OWR include garments that have wool content and other fabrics also. For example, coats, jackets and outerwear. They are bought at the rate of $20 \mathrm{Rs} / \mathrm{kg}$.

- Garbage refers to all garments that are of no use of wool recyclers example jeans, T-shirts, shirts etc. 


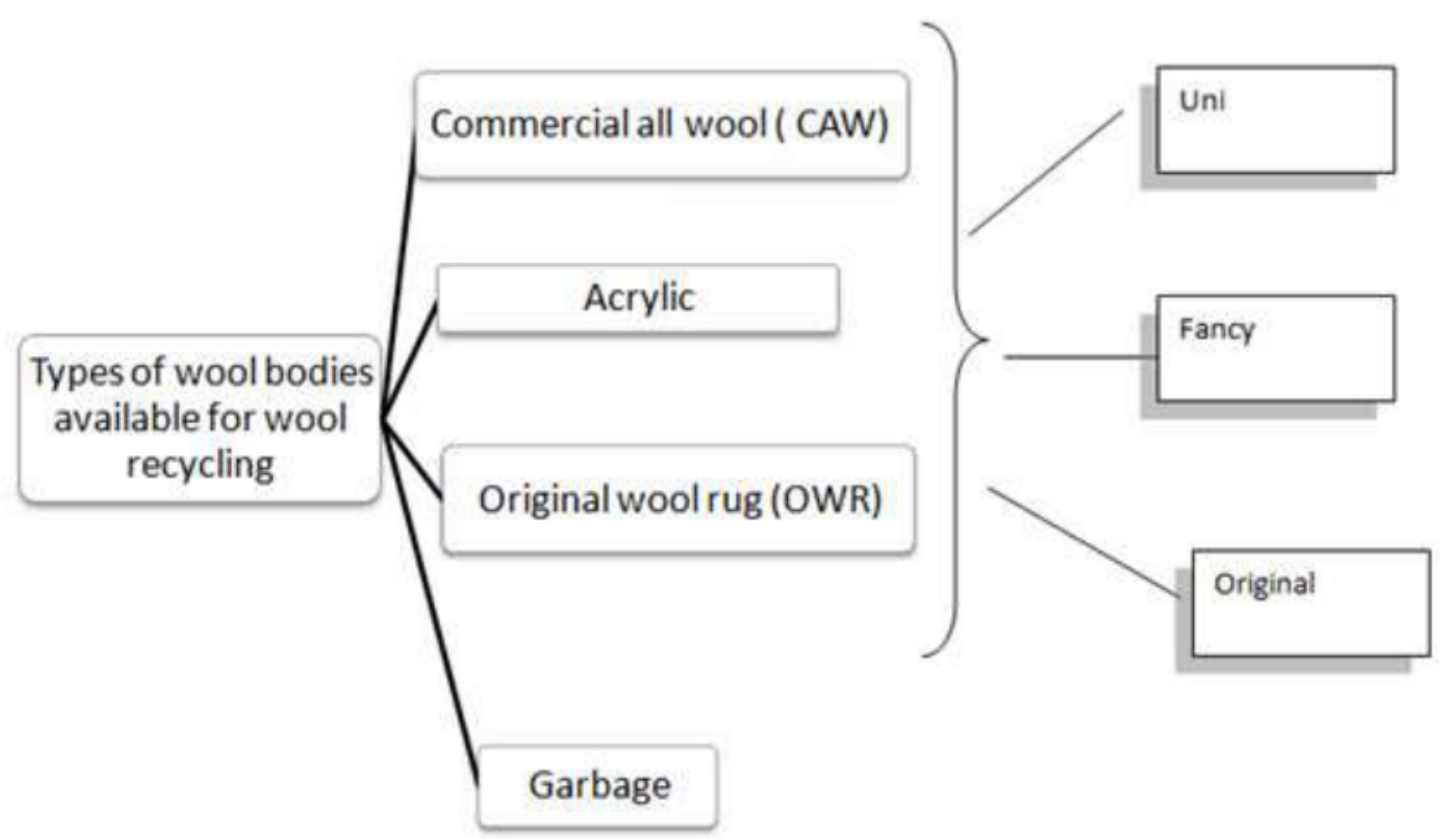

Figure 1 Classification of types of raw material available for wool recycling

Further classification of each category is:

- Uni: A bale that has single colored garments.

- Fancy: A bale with garments that have more than color thread, for example, mixed color checks, tweeds etc. Generally they are more in number when the shipment is received by the importers. These bales are sorted according to their base colors. They are used to make the fabric used in the base of the blankets.

- Original: A bale which has a mixture uni and fancy.



Photo 1 A worker opening a bale with bright colored garments bursting out of the vacuum pack

The factory owners have their chosen shortlisted suppliers from whom they buy the vacuumed packed bales, which they call "Wool Body". They choose the supplier on the basis of the quality delivered by them. Good quality bales are defined as the bales that have garments of higher wool content and are bright in colors. Color of the garment is one of the most important criteria according to the mill owners. There is a huge demand for bright colored threads, for example, bright reds, pinks, greens etc.

After the bales are opened the process followed can be represented as below. 


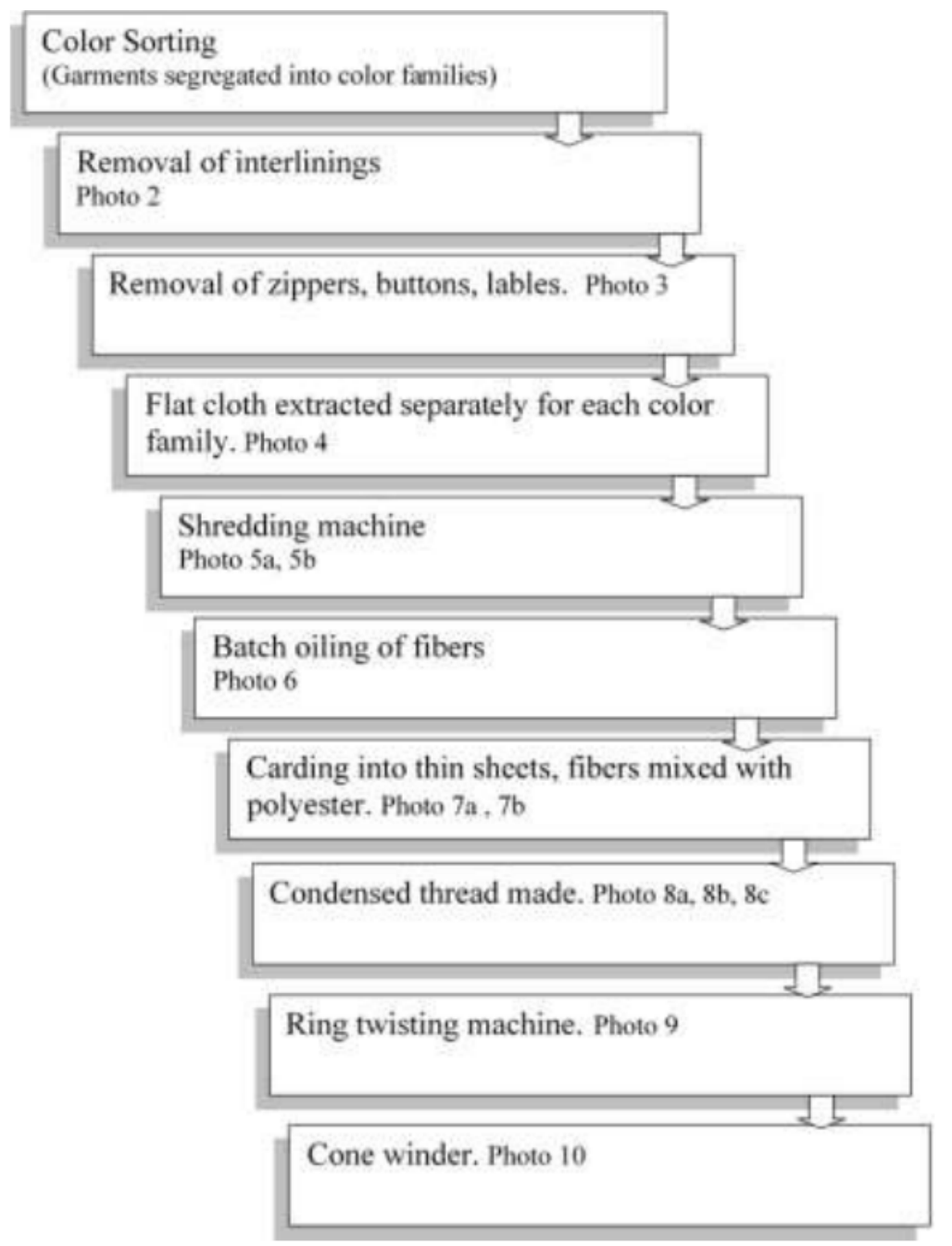

Figure 2 Process workflow of wool recycling to shoddy yarn.

\section{PHOTO DOCUMENTATION OF THE PROCESS}



Photo 2 A woman in her mid 70's separates linings of almost 500 blazers and coats in a day with a vegetable cutter. 




Photo 3 Women sit amongst the endless queue of clothes which lead to more ceiling touching heaps, sorting them and taking out zippers, buttons and other accessories from them and converting the garments to fabrics

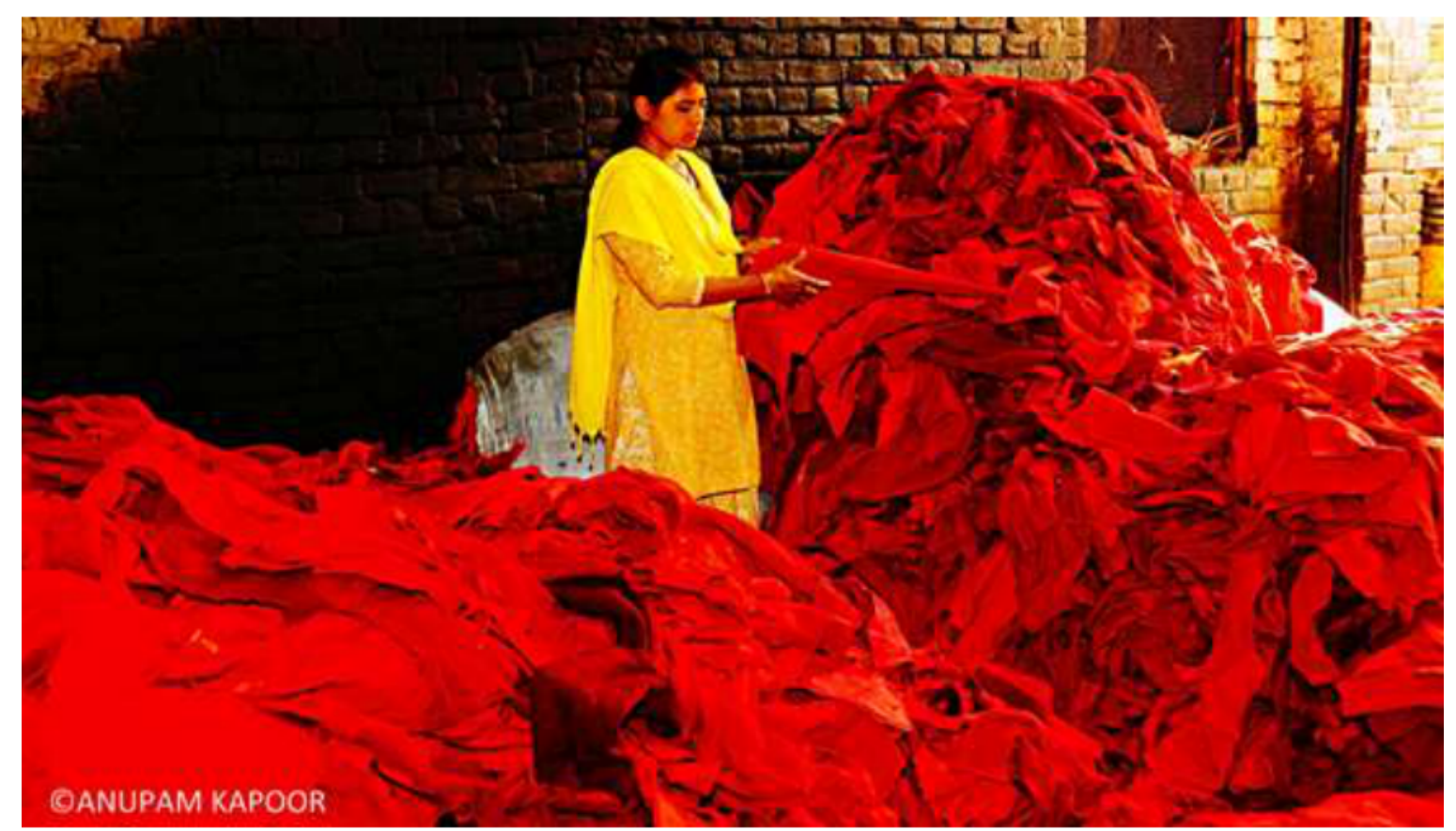

Photot 4: Different colored stacks are then made 


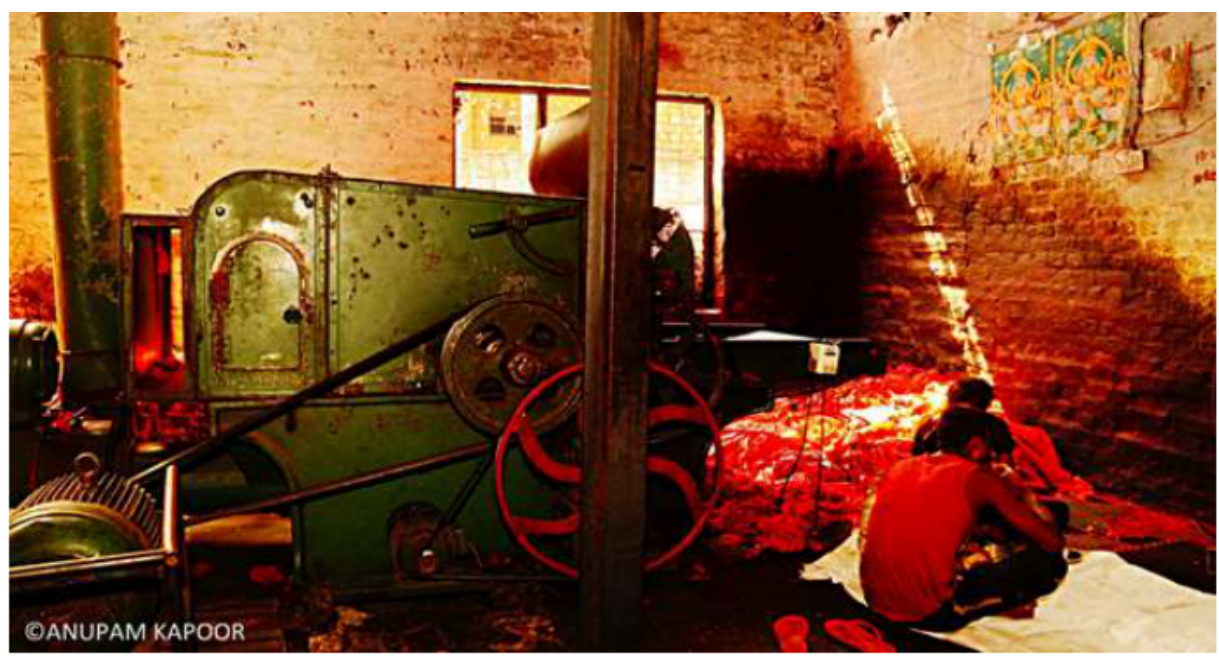

Photo 5a: The process is now taken over by male workers, they feed the fabric in the shredder with blessings of Vishkarma God posters adorning their workplace.



Photo 5 b: A group of workers collect the shredded fibers from the dark room where the machine throws them through the pipe. They have jaggery every day for lunch so the fibers do not accumulate in their lungs.



Photo 6: To avoid friction in the machine, the fibers are mixed with batch oil and each color is kept separately in cubicles overnight. 
The Afterlife of Discarded Woollens: Who is Recycling my Clothes?



Photo $7 \mathbf{a}$ (above) and $7 \mathrm{~b}$ (below). The fibers are then fed in the carding machine. They are mixed with polyester to archive strength. This machine was bought by the mill owner in 1990s when the Italian recycling industry was on its decline and machines were discarded in Prato.
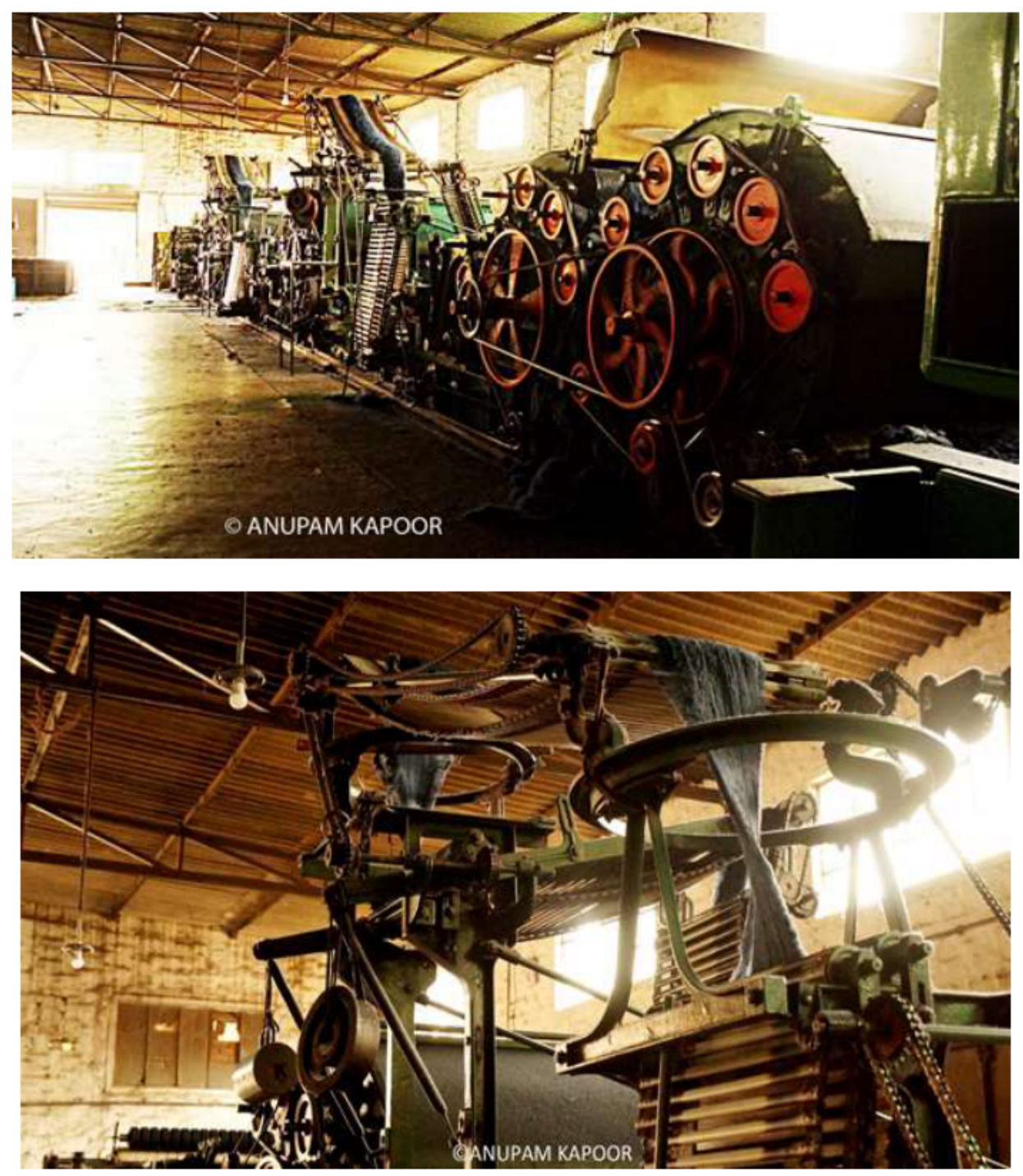

Photo 8a (above) and 8b (below). Condensed thread is made for the thin sheet which is known as "kachha dhaga" (Raw Thread) 

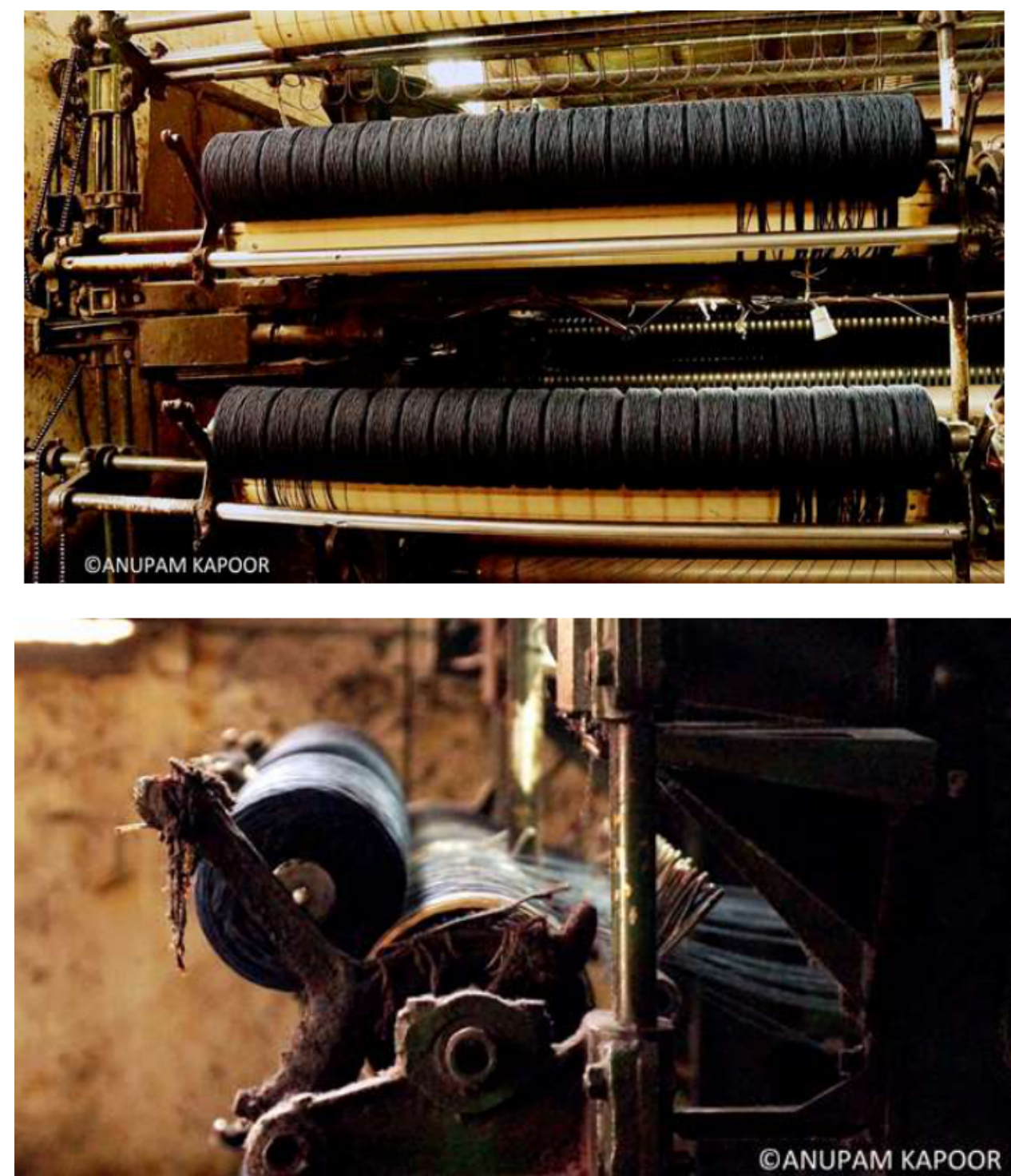

Photo 8c. Making of the raw thread



Photo 9: The thread goes into the ring twisting machine where the yarn is twisted to have a better strength. 
The Afterlife of Discarded Woollens: Who is Recycling my Clothes?

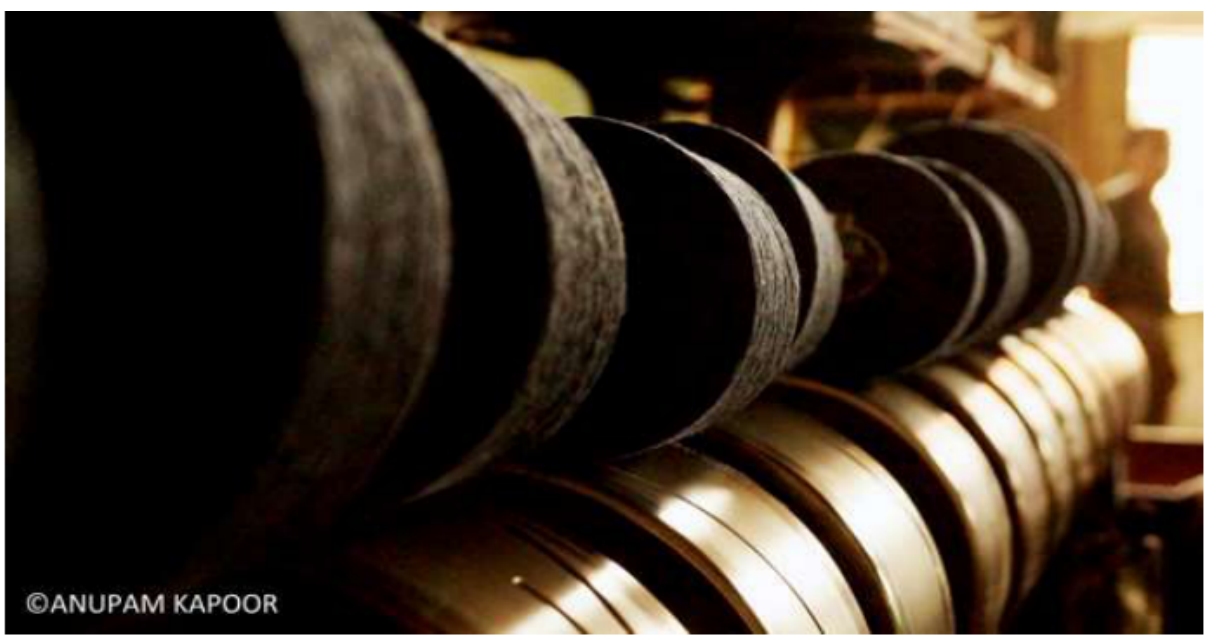

Photo 10: Cone winding machine to make the cones ready.

\section{Worker Condition}



Photo 11: Making a pit to sit between an ocean of second-hand clothes, a woman feeds her baby while separating zippers from the garments. This place, she believes, is safe for her baby as it is full of quilted clothes.



Photo 12: Her daughter plays happily with the zippers as she slides from one of the slides that she made from a clothing heap, occasionally tasting them. The factory does not have child labour but the kids are allowed with their mothers otherwise the mothers would not come to work. 


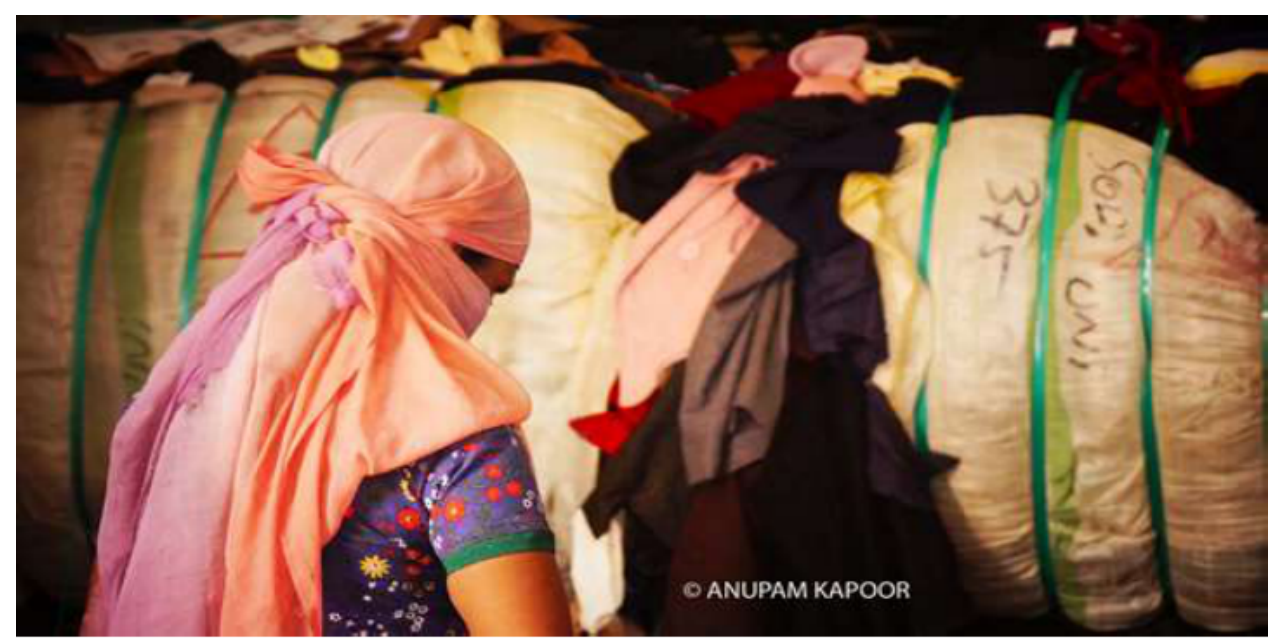

Photo 13: The disease typical to the shoddy trade is, "shoddy fever". The amosphere is bound to be full of fible because of open machines and open shredding of fabrics, constantly taken in by the workers. These fibers are reffered to as "devil's dust". Many of the workers were affected by this along with the children who accompany their mothers to work. Identified by Charles Thackrah in 1832, the symptoms of this illness are headaches, dryness and breathing problems.

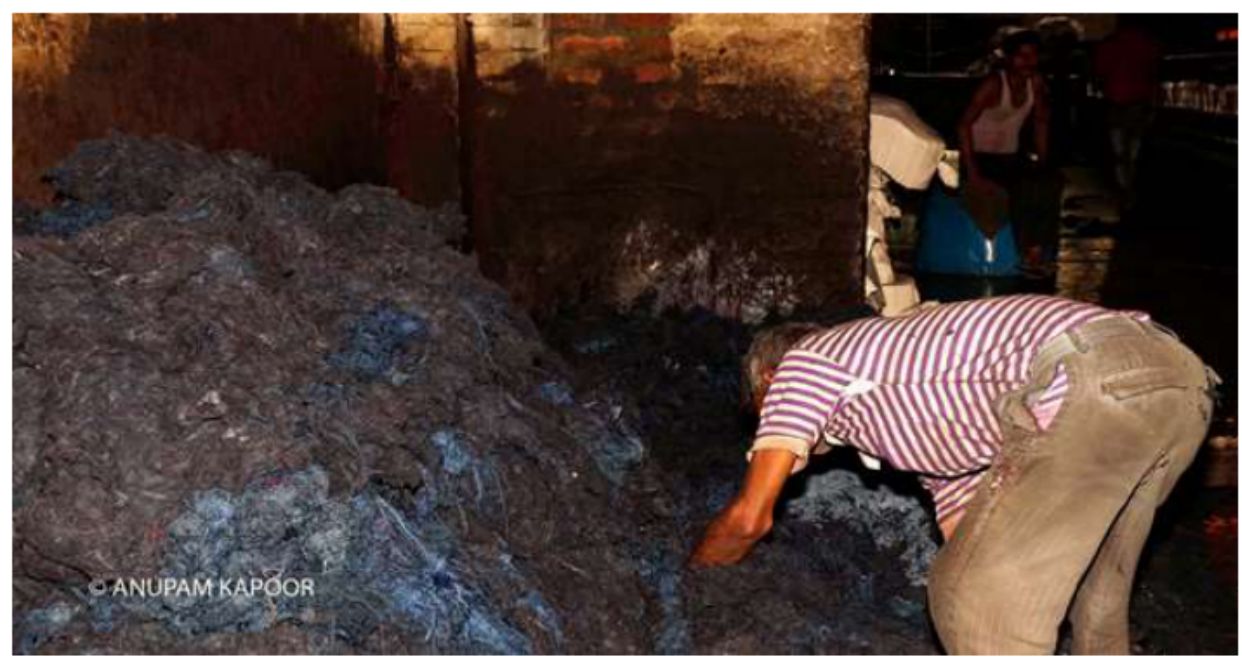

Photo 14: Ironicaly, a person working in mountains of waste clothing working with the batch oiled fibers in his tattered daily work clothes. He changes them when his working hours are over.

\section{PRESENT SCENARIO}

The presence of this business is very much visible in the town. As soon we enter Panipat, trucks loaded with woolen scrap, streets lined with colorful small waste fabrics "katrans" are there. The city immerged as a recycling hub around 1925 when there was a small industrial town in Italy, Prato had a shutdown. Panipat mill owners started to make cheap shoddy blankets from recycled wool with the discarded Italian machinery. The city's late emergence as the "cast - off capital" of the world was a home to around 400 recycling mills with its peak in 2010. 


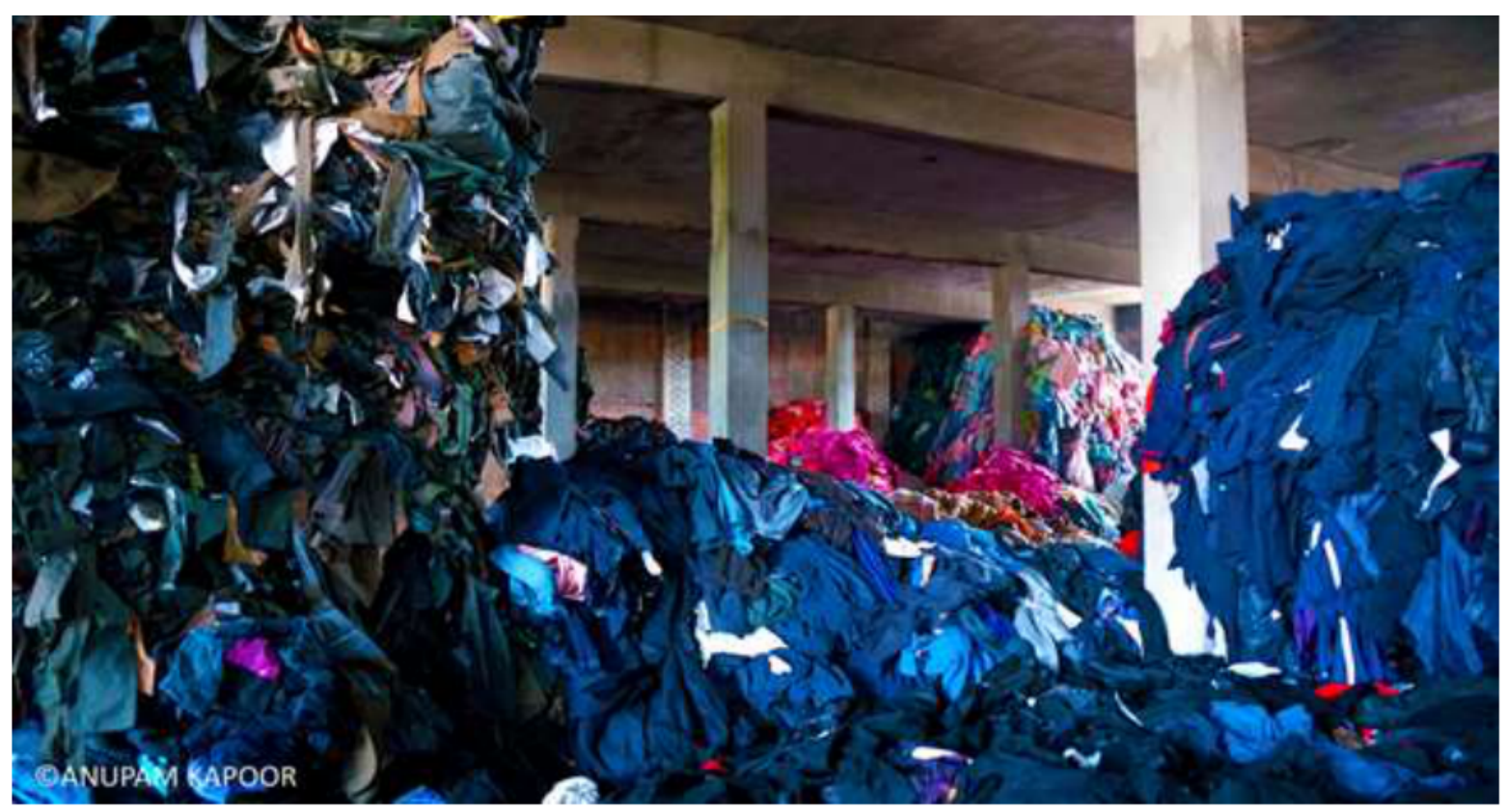

Photo 14: Endless ocean of second-hand clothes lie in ceiling touching stacks waiting to be recycled. In many factories that have shut down, the clothes are still there.

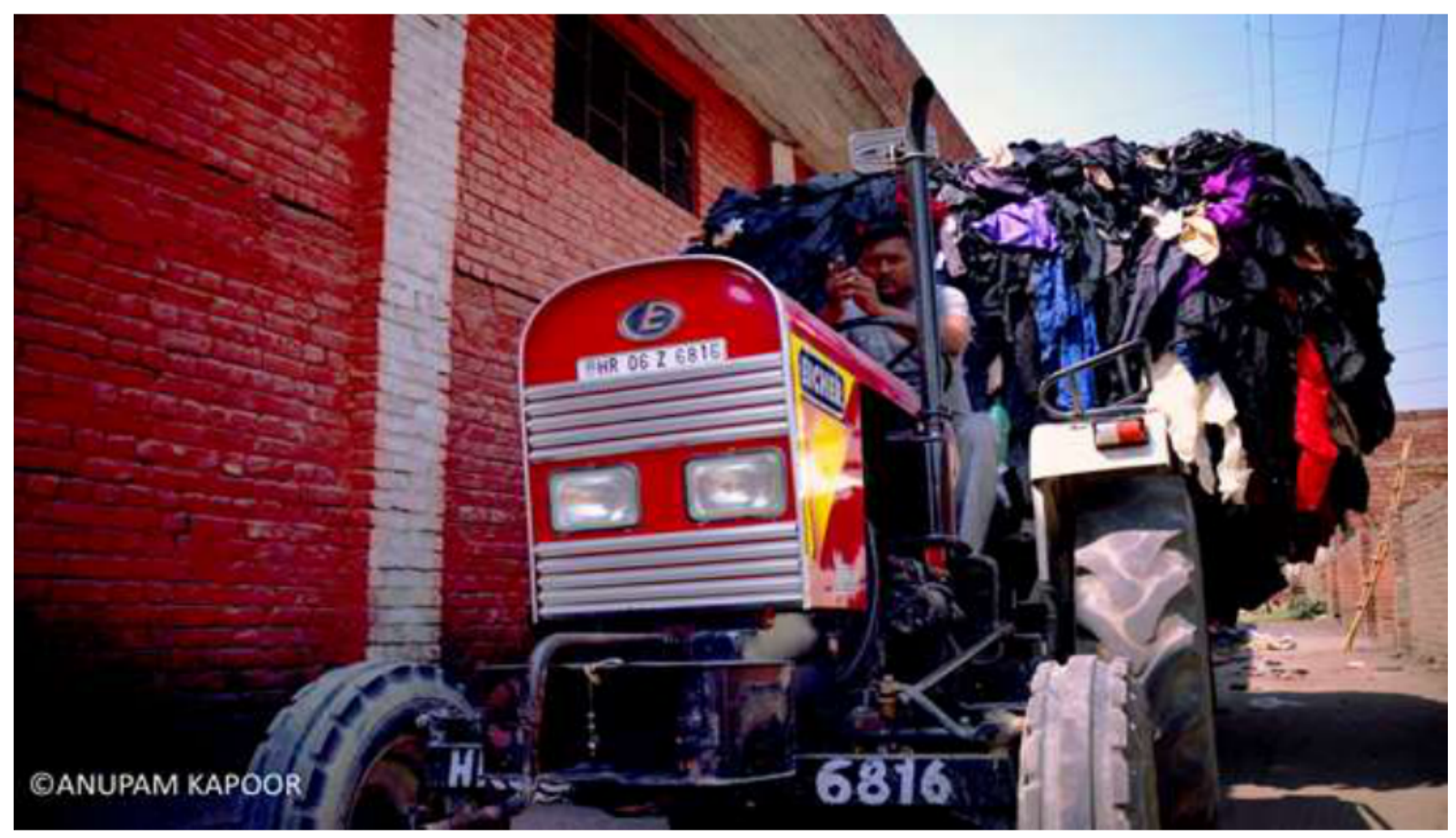

Photo 15: A tractor trolley overloaded with polyester linings waits to leave for the polyester recycling unit.

Today, the industry is on its decline. Cheaper polyester made blanket made by Chinese machinery has replaced demand for the shoddy blanket. The present scenario includes shutting down of mills, mills running on part capacities, mills reducing their production or shifting production to the polyester blanket. From 400 mills, there are now less than a 100 operational. The business has been over sighted by the government and there has been a lack of investment and efforts from the mill owners towards machinery up gradation. Had there been some basic upgrading, standards might have risen. The industry could have marketed the shoddy blanket as an environmentally conscious decision by the buyers as compared to the polyester blankets. 
But looking at the sweat shop condition, the polyester counterpart seems to be a better option. It is made in decent factories with good worker environment.

According to a mill owner "only $10 \%$ demand for shoddy blankets and shoddy making factories are remaining, rest is all shut or about to shut. The industry is not doing well."

However, the mill owners who had orders of government supply are unaffected. According to a mill owner," The industry slump has not affected us, we continue to be working on our previous capacities. We import around $1 \mathrm{Lakh} \mathrm{kg}$ of used clothing in a month and make 70,000 $\mathrm{kg}$ of shoddy yarn out of it. The raw material that we used to get at 45-50 Rs per kg in 2002 is available at 20 Rs per $\mathrm{kg}$ now. You can imagine how much waste western countries are producing"

When asked about the affect of diminishing shoddy industry on global recycling, a mill owner commented, "Everyone knows that there is an increase in global waste, the world must have found some new ways to recycle, which we are unaware of. Otherwise it is impossible to contain so much of waste. If they are not recycling, they must be throwing in the oceans or burning. Sab samunder mai jayega (everything will end up in the oceans!) "

\section{STORY OF THE CASHMERE WOOL}

Among the Panipat mill owners, there is a new term that has become popular, "Kashimira", as they call it. They refer cashmere wool as Kashmira. The piles of CAW have the maximum wool content and have jumpers and garments of $100 \%$ cashmere wool which has a high demand in the Italian recycling market. The mill owners sort 100\% cashmere garments and keep them separately in lockers or small locked rooms hidden in their office and covered with curtains. The factory owners or very few trusted employees are allowed to enter the room which is always locked. This is the new way the mill owners are making profits as this is one of the most expensive wools and they get a price of almost $1200 \mathrm{Rs}$ per $\mathrm{kg}$ by exporting to Italian buyers. Some factory owners have announced incentives and awards for workers who find out cashmere from the opened bales. Others have employed separate highly paid manpower to find cashmere garments in the bales.

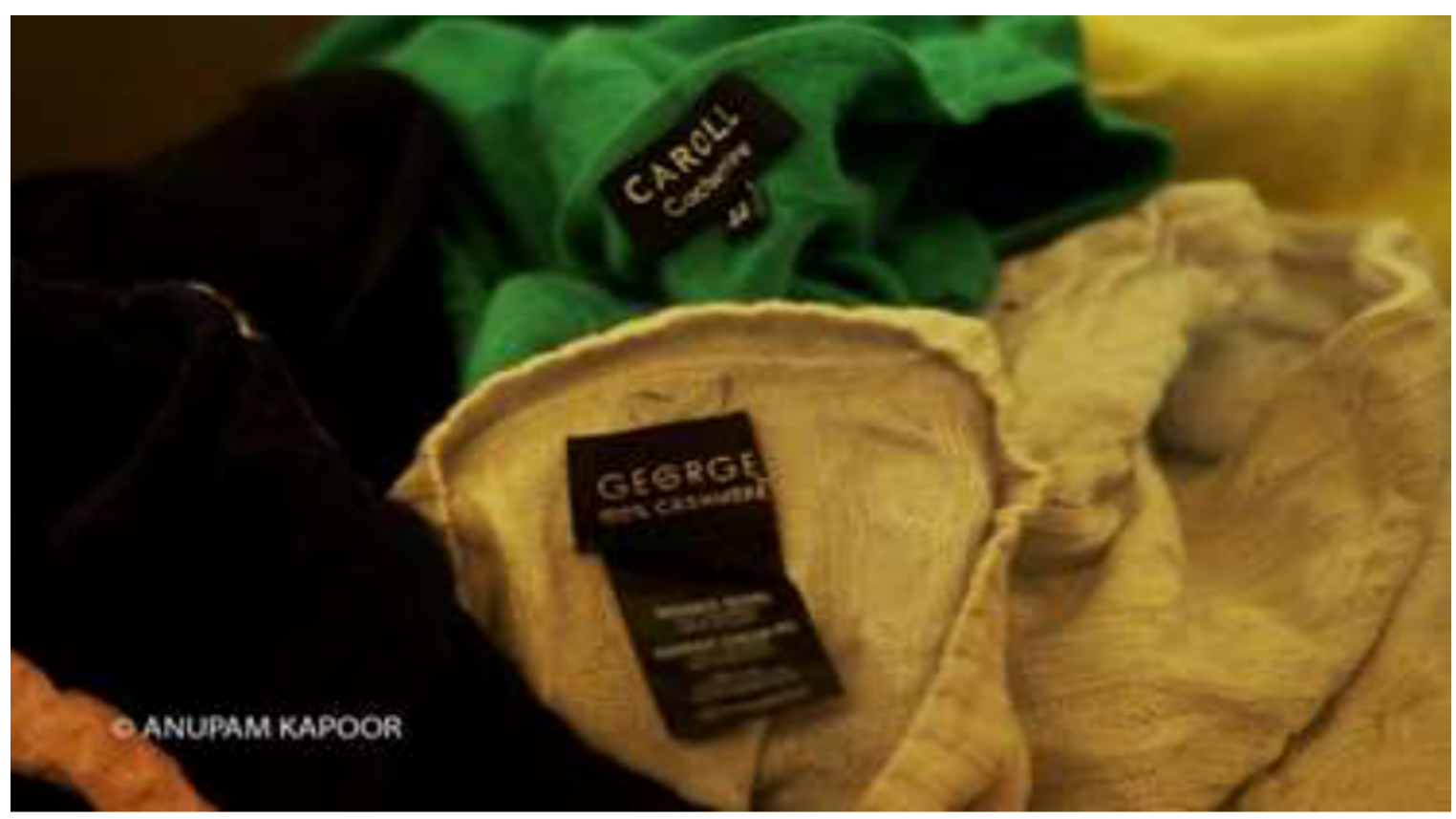

Photo 16: 100\% cashmere content sweaters form the lockers of the mill owners. 
Quoting a mill owner, "Due to unavailability of cashmere wool recycling machines in Panipat, we export cashmere to Italy. We did not know about this heera in koyele ki khan (diamond in the heap of coal) before 2012. It is a great asset to us. We purchase CAW bales specifically for this purpose. We filter cashmere from them and then pass on to the remainder to the factories who work with CAW processing. We export around $10000 \mathrm{kgs}$ of cashmere wool in a year."

\section{CONCLUSION}

According to a thekedaar (contractor) "What we are doing here has much more importance than the relief blankets. We are absorbing global waste which is very important to the environment"

"The industry can never die and would always be there till the time we have orders from the government agencies and big charitable organizations. All big charitable organizations prefer shoddy including Red Cross and other big government organizations buying refugee blankets. Till the time they are giving orders, the complete shutdown is not possible. Shoddy has no replacement. People who know the benefits of shoddy will always buy it." A mill owner states.

With new clothes getting as cheap as the second hand, worldwide demand for used clothing is decreasing. Many countries including African sub continent are discouraging import of second hand as they want to work towards the growth of their domestic industries. Literature has argued consumption of clothing as an expression of one's social self, forming different identities that we wish to portray and image of our culture. The clothes that have different identities now lie in a heap of dirt. The mountains of clothing piles in Panipat units represent the lost story and image in each garment. The women shredding them and the person donating them have no idea of what is happening at the either end. The person donating them is clearing his/her guilt and connecting to the environment by disposing the garment in the best possible way. The woman slashing them is feeding raw material to the machinery everyday not knowing that she is contributing to the environment. The workers do have notions and images in their minds of the garments which are culturally inappropriate to them and the people wearing them in "foreign" countries. The notions that these worker attach to the clothing they recycle discussed by Norris in 2012 throw light on the innocence of these workers with regards to the environment.

Weighting the social aspect of this industry, it is arguable weather the decline of Panipat shoddy is positive, looking at the worker condition and unwillingness of the mill owners to upgrade facilities or negative, looking at the increasing global clothing waste. The polyester substitutes are produced in much better facilities comparatively. But the pilling global waste is the biggest environment threat in the making.

\section{REFERENCES}

[1] Abraham, N, The apparel aftermarket in India-a case study focusing on reverse logistics. Journal of Fashion Marketing and Management: An International Journal, 15(2), 2011, pp 211-227.

[2] Acharya, N, "India emerges top importer of used clothes", available at https://www.business-standard.com/article/current-affairs/india-emerges-top-importer-ofused-clothes-115100800540_1.html (accessed 20 July 2018),2015

[3] Bianchi, C., \& Birtwistle, G, Consumer clothing disposal behaviour: A comparative study. International Journal of Consumer Studies, 36, 2012, pp 335-341. doi:10.1111/j.14706431.2011.01011.x 
[4] Goworek, H., Fisher, T., Cooper, T., Woodward, S., \& Hiller, A, The sustainable clothing market: an evaluation of potential strategies for UK retailers. International Journal of Retail Distribution Management, 40, 2012, pp 935-955.

[5] Gupta, V., \& Khare, A. (2011). Value Creation in post-consumer apparel waste: a study of urban-rural dynamics in India, [Online] Available from.

http://process.arts.ac.uk/sites/default/files/varsha-gupta.pdf [Accessed: 30th January 2018].

[6] Hawley, J.M.,Digging for diamonds: A conceptual framework for understanding reclaimed textile products. Clothing and Textiles Research Journal, 24(3), 2006, pp.262-275.

[7] Kim, G, "Used clothes: Why is worldwide demand declining?" , available at https://www.bbc.com/news/business-42777804 (accessed, 12 August 2018),2018

[8] Koch, K., \& Domina, T, The effects of environmental attitude and fashion opinion leadership on textile recycling in the US. International Journal of Consumer Studies, 21(1), 1997, pp 1-17.

[9] Morgan, L. R., \& Birtwistle, G, An investigation of young fashion consumers' disposal habits. International journal of consumer studies, 33(2), 2009, pp 190-198.

[10] Norris, L, Cloth that Lies: the secrets of recycling in India. Berg, 2005

[11] Norris, L.,Trade and transformations of secondhand clothing: Introduction. Textile, 10(2), 2012, pp.128-143.

[12] Norris, L.,Economies of moral fibre? Recycling charity clothing into emergency aid blankets. Journal of Material Culture, 17(4), 2012, pp.389-404.

[13] Norris, L.,Shoddy rags and relief blankets: Perceptions of textile recycling in north India. Economies of Recycling: the global transformation of materials, values and social relations, 2012, pp.35-58.

[14] Norris, L, The limits of ethicality in international markets: Imported second-hand clothing in India. Geoforum, 67, 2015, pp.183-193.

[15] Ajay Verma and Dr. Anshul Gangele, Green Supply Chain Management Empirical Study For "Closing the Loop", International Journal of Production Technology and Management (IJPTM), Volume 3, Issue 1, January- December (2012).

[16] O'Reilly, S. and Kumar, A.,Closing the loop: An exploratory study of reverse ready-made garment supply chains in Delhi NCR. The International Journal of Logistics Management, 27(2), 2016, pp.486-510.

[17] Rebello, J, "World's cast-off capital goes from riches to rags", available at https://timesofindia.indiatimes.com/home/sunday-times/deep-focus/Worlds-cast-offcapital-goes-from-riches-to-rags/articleshow/49612121.cms (accessed, 10 September 2018),2015

[18] M. C. S. Reddy. A Multi-Objective Approach For Optimum Quota Allocation to Suppliers in Supply Chain. International Journal of Advanced Research in Engineering and Technology, 6(11), 2015, pp. 42-49. 
The Afterlife of Discarded Woollens: Who is Recycling my Clothes?

[19] Rivoli, P.,The travels of a t-shirt in the global economy: An economist examines the markets, power, and politics of world trade. New preface and epilogue with updates on economic issues and main characters. John Wiley \& Sons, 2014

[20] Shim, S, Environmentalism and consumers' clothing disposal patterns: An exploratory study. Clothing and Textiles Research Journal, 13, 1995, pp 38-48.

[21] Saini, N., Yadav, S. and Rose, N.M., 2018. Shoddy woollen industries: Say no to dye chemicals. IJCS, 6(2), pp.1572-1576. 